\title{
O TEN E A NEGRITUDE FRANCÓFONA NO BRASIL \\ Recepção e inovações
}

\section{Muryatan Santana Barbosa}

Salvo melhor juízo, a primeira referência à negritude francófona no Brasil ocorreu no primeiro número do jornal oficial do Teatro Experimental do Negro (TEN), ${ }^{1}$ chamado Quilombo, em dezembro de 1948. Trata-se de uma nota informando a existência de um grande acontecimento cultural no "pensamento negro" mundial: a revista Présence Africaine. De acordo com a nota (não assinada):

Não temos notícia de outra publicação negra que iguale em importância cultural a essa "Présence Africaine", editada em Paris e Dakar. O escritor mundialmente famoso André Gide, que ao lado de Albert Camus, Richard Wright, Jean-Paul Sartre, e outros - figura como patrono da revista, fez a apresentação num artigo apelando para se ouvisse o que o negro tinha a dizer, desde que há tantos séculos ele

Artigo recebido em 07/06/2011

Aprovado em 17/09/2012 vinha sendo explorado sem uma oportunidade. E os negros da Sorbonne, em Paris, ou de Dakar, Cuba, Haiti ou Norte-Americanos estão dizendo coisas graves, seríssimas, decisivas a respeito dos temas mais variados que interessam ao comportamento do homem intelectual, vinculado a marcha perene do espírito e do pensamento em sua inquietude e insatisfação criadora. [...] "Présence Africaine" está em seu quarto numero de revista mensal significando o primeiro passo numa distância nova, uma etapa histórica na influência do pensamento negro na evolução do mundo (apud Nascimento, 2003, p. 21).

Présence Africaine foi uma das revistas culturais mais respeitadas na segunda metade do século XX. Criada em 1947, era a culminação de uma série de tentativas anteriores de estudantes negros, antilhanos e africanos em fundar uma revista que pudesse 
exprimir uma visão positiva da identidade negra na diáspora, como as revistas: Légitime Défense (1932), dirigida pelos escritores antilhanos René Menil, Jules Monnero, Étienne Léro e outros; Étudiant Noir (1934), dirigida pelos literatos antilhanos Aimé Césaire, o guianense Léon Damas e o senegalês Léopold Sédar Senghor e outros estudantes, como Aristide Maugée, Birago Diop, Ousmane Soce e os irmãos Achille. Como observa o antropólogo Kabengele Munanga (1988, pp. 42-43), no imaginário dessas revistas, já pesavam alguns elementos marcantes, que seriam temas fulcrais da negritude francófona: a) uma visão diaspórica do negro; b) necessidade do negro se colocar como ser autêntico, sujeito de sua ação social; c) reivindicação da liberdade criadora do negro; d) volta às raízes africanas. Estes eram os temas fundamentais que definiam a literatura negra, especialmente a francófona, enquanto literatura engajada, nas décadas de 1940 e 1950 (Wauthier, 1973, pp. 154ss). ${ }^{2}$

A negritude francófona foi um movimento artístico, estético e político dos anos de 1940 e 1950, baseado no ativismo de poetas negros de expressão francesa, como Léon-Damas, A. Césaire, $S$. Senghor, É. Léro, A. Diop e outros. Segundo Césaire, tratava-se de uma "tomada de consciência" da especificidade do ser negro. Em suas palavras: "negro estou, negro permanecerei" (Césaire, 2005, p. 28). Todavia, diz o autor, a consciência desta especificidade não era um enclausuramento, mas uma abertura para o universal e para a valorização do Homem, ao mesmo tempo em que carregava uma dimensão revolucionária ao afirmar a presença de uma parte antes ignorada da humanidade. $\mathrm{O}$ próprio termo "negritude", aliás, reflete bem este conteúdo, ao menos conforme utilizado pela primeira vez pelo próprio Césaire no célebre Cahier d'un retour au pays natal [Caderno de um regresso ao pais natal, 1939]:

[...]

minha negritude não é nem torre nem catedral ela mergulha na carne rubra do solo ela mergulha na ardente carne do céu ela rompe a prostração opaca de sua justa paciência. (apud Senghor, 1948, p. 57)
Como observa Claude Wauthier (1973, p. 38), para os autores da negritude, a língua francesa e a expressão de uma alma africana, seja da Martinica ou da África negra, formariam uma junção cultural rica, com apropriação da sintaxe europeia e o ressurgimento de valores e representaçôes socioculturais que expressariam a unidade negra, assim como as origens diversas dos autores do movimento.

A Présence Africaine tinha em seu grupo coordenador a liderança de Alioune Diop e sua mulher, Christiane Diop, contando com a colaboração de alguns dos principais nomes da negritude francófona, como Aimé Césaire, Jacques Rabémananjara, Leopold Sédar Senghor, Léon-Gontran Damas e Aké Loba. Nesta empreitada, estes destacados jovens intelectuais antilhanos e africanos conquistaram o apoio de intelectuais de destaque internacional à época, como André Gide, Richard Wright, Albert Camus, Emmanuel Mounier e Jean Paul-Sartre.

Por esta proximidade com as pessoas que organizaram a negritude francófona, os primeiros números da Présence, entre fins da década de 1940 e início de 1950, eram marcados pelos ideais deste movimento cultural. Nesse sentido, Senghor (1992, p xi) afirma que a revista foi o primeiro instrumento da negritude francófona. Como resumiu Roger Bastide (1961, p. 84), tratava-se de uma luta contra a aculturação europeia, que dava especial atenção à valorização de suas raízes africanas, como contraponto necessário à "cultura ocidental". Nessa perspectiva crítica da negritude francófona está contida nos dois sentidos básicos e inter-relacionados do termo negritude, conforme abordados por Munanga (1988, p. 44). O primeiro era a noção que dominava antes da Segunda Guerra Mundial, qual seja, o simples reconhecimento do fato de ser negro, uma de aceitação de seu destino, história e cultura - princípios formadores de uma identidade negra positiva e orgulhosa. Esta visão da negritude foi definida, posteriormente, por Aimé Césaire, entre outros, como uma personalidade cultural africana, cujos aspectos primordiais seriam a identidade, a fidelidade e a solidariedade para com os povos negros de todo o mundo. $\mathrm{O}$ segundo sentido da negritude, segundo Munanga, resultou de um processo que aos poucos alterou seu significado até ganhar uma dimensão política próxima àquela do 
pan-africanismo: como luta simbólica pela emancipação dos povos negros do colonialismo ocidental.

Publicados no imediato pós-Guerra, os números iniciais de Présence Africaine traziam características de ambas as definições, um exemplo de certa complementaridade entre estas, conforme sugerido por Munanga. Nesse sentido, atentando para os poemas de L. S. Senghor, por exemplo, Chant de initié (n. 1, nov. dez., 1947), Congo (n. 4, $2^{\circ}$ trim., 1948), La phrase ensemble (n. 4, $2^{\circ}$ trim., 1948), Le Kaya-Magan (n. 5, $1^{\circ}$ sem., 1948), Munanga chama atenção para uma identidade comum da África negra. Em suas palavras, uma "personalidade cultural africana", tida como especificidade e caminho próprio a ser resgatado pelos negros, em busca da universalidade. Bernard Mouralis (1992, p. 6), por sua vez, enxerga como a marca dos primeiros números a militância anticolonialista, voltada para a defesa da consciência negra e, concomitantemente, para a formação de um universalismo humanista.

Anunciada com regozijo em dezembro de 1948, a Présence Africaine volta a ser noticiada, de forma mais discreta, nos próximos números do Quilombo, em maio e junho de 1949, informando apenas o lançamento de outros exemplares da revista. Os colaboradores e intelectuais do TEN, no Quilombo, não mais se reportam aos autores da negritude, mesmo quando tratam de temas relativos à arte e à cultura negra e/ou afro-brasileira, como nos ensaios de Abdias do Nascimento ("Nós", n. 1), Edison Carneiro ("Como se desenrola um festa de candomblé", n. 1) e Ironides Rodrigues ("Exotismo literário de Paul Morand", n. 2).

De fato, entre dezembro de 1949 e junho de 1950, os únicos artigos em que se vislumbra uma aproximação da temática abordada na poesia da negritude francófona são do poeta argentino Efraín Tomas Bó: "Poesia afro-americana" (dez. 1948) e "O ator negro" (maio 1949). No primeiro, por exemplo, Efraín se refere a uma subjetividade negra específica, como "manifestação íntima ou interior"; fala também dos "motivos líricos puros" da literatura negra, cuja origem residiria "na alma do negro, em sua emoção diferenciada, em seu temperamento espiritual submetido ou adaptado ao clima de convivência americano". Em outra passagem, Efraín retoma o argumento nas seguintes palavras: "Vol- tamos a repetir que nossas suposiçôes permitem afirmar que existem caracteres intrínsecos da alma lírica do negro em sua manifestação artística e que estes caracteres, oriundos de seus sentidos profundos, só o negro o pode sentir e expressar". São sentimentos que, segundo o poeta argentino, estariam ligados à predominância do conteúdo sensível sobre a vivência, do estado sensual sobre a plenitude do prazer, da dor sobre a serenidade do pensamento (Efraín Bó, 2003a, p. 23).

Esta argumentação acerca dos valores específicos do negro é retomada por Efraín no segundo texto aludido, evocando o teatro negro como instrumento de desenvolvimento dos "valores autônomos da raça de cor":

[...] o negro deve ir à cena não como um ator a mais, de pigmento escuro, mas sim no uso de uma profunda subjetividade, no desenvolvimento de uma singular possibilidade histriônica $[\ldots]$. O homem negro, - como todas as dimensões de espírito, alma e corpo - pode representar qualquer obra onde sobressaiam os movimentos e a transcendência emocional da vida. [...] O Teatro Experimental do Negro vai-se integrando como grupo, edificando-se sobre uma razão de sobrevivência que está para além dos seus passos presentes, e fortifica seu organismo na certeza de que assim como o negro traz ao teatro brasileiro sua robustez, o teatro, ecumenicamente falando, é parte do desenvolvimento dos valores autônomos da raça de cor (Efraín Bó, 2003b, p. 33).

A proximidade desses comentários com as abordagens da poesia da negritude francófona - em sua ênfase da especificidade da subjetividade negra e a data de publicação do primeiro dos seus ensaios, em dezembro de 1948, poderiam sugerir a hipótese de que foi o poeta argentino quem primeiro trouxe ao contexto da luta afro-brasileira a concepção dessa literatura, mas não há dados suficientes para embasar tal afirmação.

Uma aproximação mais direta, entretanto, pode ser confirmada no terceiro número de Quilombo, publicado em junho de 1949. Há duas cartas telegráficas (uma assinada pela redação [25/4], 
outra pelo redator-chefe J. Schwder-Oriol [26/04]) da direção da Présence Africaine para o líder do TEN, Abdias do Nascimento, em resposta a mensagens anteriores de Abdias (não publicadas). A primeira aborda questôes relativas à permuta de artigos e de publicidade; a segunda indaga a possibilidade de Abdias se tornar colaborador permanente da Présence (apud Nascimento 2003, p. 36). Dada a característica pró-ativa de sua liderança no TEN, é difícil crer que Abdias não tenha concretizado este contato inicial em algo prático. É provável, então, que os primeiros exemplares da revista francesa tenham chegado ao TEN no segundo semestre de 1949, quando Abadias manteve contato com a redação da Présence.

A recepção dos ideais da negritude francófona no teatro negro se adensou em fins de 1949, por ocasião da visita do filósofo e escritor Albert Camus ao Rio de Janeiro. O próprio Quilombo atesta tal fato num artigo de janeiro de 1950, intitulado: "Roteiro negro de Albert Camus no Rio" (p. 69). Destaca-se aqui o interesse do escritor franco-argelino, apoiador da negritude francófona e conselheiro da Présence Africaine, em conhecer a vida dos negros cariocas. Camus teria frequentado diversos terreiros na cidade, assim como boates e clubes em que os frequentadores eram majoritariamente negros. Camus visitou ainda as instalaçóes do TEN, onde assistiu a uma encenação resumida da sua peça Calígula.

Vale dizer que, segundo o conhecido produtor e intelectual Haroldo Costa (2003), membro do TEN, havia na época um intenso diálogo intelectual entre os integrantes do teatro e os colaboradores mais próximos. Não se tratava de reuniōes convencionais, mas de conversas informais entre Ironides, Guerreiro Ramos, Abdias, Sebastião Rodrigues Alves e mais duas ou três pessoas, entre elas, provavelmente, Efraín Thomás Bó, colaborador do TEN e amigo de seus líderes, e Gerardo Mourão, membro de uma congregação de poetas por eles organizada Santa Hermandad de la Orquídea (Mourão, 2003). $\mathrm{O}$ jovem Ironides Rodrigues foi uma figura importante neste contexto - o "paladino da negritude", nas palavras de Costa. Foi ele quem, efetivamente, se apoderou da temática da negritude francófona, tornando-se um divulgador desta no teatro negro.
O café e bar Vermelhinho, então localizado em frente à Associação Brasileira de Imprensa (ABI), onde o TEN costumava realizar seus congressos e reuniōes formais, era o lugar onde todos se encontravam. Costumeiramente frequentado por estudantes da Escola de Belas Artes do Rio de Janeiro, por ali circulavam também pessoas ligadas a organizaçóes de esquerda, intelectuais e artistas em geral.

$\mathrm{Na}$ quinta edição de Quilombo, em janeiro de 1950, fica explícito como as ideias da negritude francófona foram assumidas pelo grupo. Não por acaso, sob auspícios de Ironides Rodrigues, que atesta essa recepção em dois textos publicados neste número: uma tradução resumida do ensaio "Orpheu negro", de Jean Paul-Sartre, e o artigo "Cruz e Souza em outro idioma", destacando o "grande coeficiente de alma negra que existe em sua poesia". O artigo célebre do filósofo francês, em que ele dava sua versão teórica da negritude, foi escrito, originalmente, como apresentação do livro organizado por Leopold $S$. Senghor, com os principais nomes do movimento da negritude à época: Anthologie de la nouvelle poésie négre et malgache (1948), que reuniu, além do ensaio de Sartre, poesias de quinze jovens autores negros, africanos e antilhanos, como A. Césaire, o próprio L. Senghor, Léon-G. Damas, B. Diop, D. Diop e J. Rabémananjara. Por esta razão, é difícil crer que, ao se apossar do "Orpheu negro", os líderes do TEN também não tenham tido acesso ao livro organizado por Senghor. Provavelmente isso ocorreu ou por intermédio dos contatos de Abdias com a direção da Présence, ou, no final de 1949, pelas mãos de Albert Camus, quando de sua visita ao Brasil. Seja como for, os ensaio de Ironides comprovam a familiaridade crescente do TEN com a abordagem e a temática da negritude francófona. Uma recepção que, salvo melhor júizo, se consumou no segundo semestre de 1949 mediante tal livro, assim como por exemplares da revista Présence Africaine.

Esta recepção continua é atestada também no discurso que Guerreiro Ramos fez no mesmo mês de janeiro de 1950, por ocasião da instalação do Instituto Nacional do Negro, do qual seria coordenador - discurso publicado no livro Relações de raça no Brasil (1950). Guerreiro cita explicitamente o "Orpheu negro" de Sartre. Ademais, mostra um caso particular e pioneiro do caráter reinterpretativo 
que a negritude francófona recebeu, logo de início, pelas lideranças do TEN. Isto fica evidente quando, em seu discurso, Guerreiro defende a tese de que o negro de então viveria em um mundo dicotomizado entre os valores dominantes do Ocidente e os valores de sua "cultura negra", tida por ele como algo remanescente ao mundo moderno. Essa dicotomia, segundo o autor, seria uma ambivalência psicológica que dava fundamento à subjetividade negra, considerada uma forma específica de vivência e representação do negro moderno. Diz Guerreiro Ramos:

O homem de cor viveu sempre tutelado no Ocidente. Introduziram-lhe aí e lhe deram alguns papéis para representar a até recentemente em toda a parte do Ocidente, ele permaneceu segregado em grandes aglomerados, imerso em sua mentalidade pré-lógica. Tendo ele próprio assimilado os padrōes culturais do homem branco passou a ver-se a si mesmo inclusive a sua herança cultural através dos padróes do homem branco [...]. A pesquisa sociológica e antropológica tem provado, à saciedade, esta ambivalência. Por toda a parte, onde as culturas negras estabeleceram comércio com os valores ocidentais, ela se registra. Mas esta ambivalência, embora dolorosa, é a matéria-prima da subjetividade negra. Ela tem sido para o homem de cor o aguilhão que o mantém vivo, esperto, criador. As forças da alma negra longamente representadas constituem atualmente a maior reserva de vitalidade de nossa civilização. Quando tudo nesta civilização, quase inteiramente construída pelo esforço do branco, parece gasto, quando o impulso anímico desta civilização parece totalmente objetivado, quando toda a cultura já se transformou em civilização ou em burocracia, reponta uma esperança de salvação, descobre-se neste mundo uma mina inusitada, a alma negra, a subjetividade negra. Esta é a hora do homem de cor (apud Guerreiro Ramos e Nascimento et al., 1950, p. 41).

No caso particular de Guerreiro Ramos e do TEN, há ainda outra razão que explica seu viés direcionado à negritude. Conforme o sociólogo Antonio Sérgio A. Guimarães (2002), tratava-se do pacto da democracia racial, visto que a teoria da negritude chegou ao Brasil quando o teatro negro estava consolidando sua política de alianças, com o objetivo primordial de consolidar um projeto integracionista do negro pós-Estado Novo. Nesse contexto, não era atraente, aos líderes do TEN, uma visão diferencialista da negritude, como o "racismo antirracista" proposto por Sartre em "Opheu Negro". Afinal, essa interpretação poderia "legitimar" os ataques de "racismo às avessas" e/ou o "espírito de imitação do estrangeiro", que a direita mais radical gostava de lhes impingir. ${ }^{3}$ Do mesmo modo, uma interpretação da negritude como "africanidade" ou "volta à mãe África" seria exemplo de antipatriotismo, imagem que os líderes do TEN não queriam reforçar.

Assim como Abdias, Guerreiro estava consciente deste fato. Por isso, entre 1949 e 1950, defendia uma visão conciliadora da negritude como um legado espontâneo da intelligentsia do TEN, que teria se tornado capaz de compreender e trabalhar com o "espírito de conciliação" da negritude. Essa característica conciliadora ganha uma marca patriótica exacerbada no artigo intitulado "Apresentação da negritude", publicado no último número do Quilombo, em junho de 1950. Aqui, a negritude é entendida por Guerreiro como uma subjetividade inserida nas categorias clássicas da cultura brasileira, testemunho vivo do espírito "democrático" e "humano" desta cultura, que possibilitaria ao Brasil "assumir no mundo a liderança da política de democracia racial". Em suas palavras:

O Brasil deve assumir no mundo a liderança da política de democracia racial [...]. O Teatro experimental do Negro é um movimento vanguardista de elevação cultural e econômica dos homens de cor, em cujos quadros se processa a elaboração consciente da ideologia tradicional do Brasil com respeito a relaçóes de raça no Brasil. Apresenta-se assim o país, por intermédio de uma parte de sua intelligentsia para oferecer ao mundo, uma metodologia genérica de tratamento de questōes raciais.

Esta é a nossa profunda convicção. No momento em que lançamos na vida nacional o 
mito da negritude, fazemos questão de proclamá-la com toda clareza.

A negritude não é um fermento de ódio. Não é um cisma. É uma subjetividade. Uma vivência. Um elemento passional que se acha inserido nas categorias clássicas da sociedade brasileira e que as enriquece de substância humana. Humana, demasiadamente humana é a cultura brasileira, por isto que, sem desintegrar-se, absorve as idiossincrasias espirituais, as mais variadas. E até compõe com elas a sua vocação ecumênica a sua índole compreensiva e tolerante. A cultura brasileira é, assim, essencialmente católica, no sentido de que nada do que lhe é humano lhe é estranho (Guerreiro Ramos, 2003, p. 117).

Ao focar o suposto aspecto nacional e democrático da negritude, como salienta Roger Bastide (1961, p. 89), essa visão patriótica refletia a necessidade de Guerreiro Ramos em torná-la exemplo de brasilidade. Todavia, é provável que, concomitantemente, ela respondia a razões ainda mais pragmáticas. Isso porque, em 1950, quando Guerreiro escreve este artigo, é o ano em que Gilberto Freyre estreitava seus laços com o teatro negro, participando de uma conferência em homenagem da coreógrafa e antropóloga estadunidense Katherine Dunham. A presença de Freyre neste evento, realizado no TEN em junho daquele ano, dava continuidade à sua luta parlamentar pela aprovação da Lei Afonso Arinos (votada em 1951), que incluía entre as convenções penais a prática de atos de preconceito de raça ou de cor. Essa era uma lei que a liderança do TEN alcunhou de "Segunda Abolição". Neste contexto, ao trazer uma imagem freyriana da negritude, destacando-a como uma subjetividade nacional, humana, sincretizada pela índole democrática da cultura brasileira, Guerreiro revela sua disposição em aproximar os laços intelectuais e políticos entre a liderança do TEN e o famoso escritor e político recifense. Era um ato em favor de uma aliança crucial em prol da aceitação do projeto de lei do senador Afonso Arinos, apresentado no Congresso Nacional, em 17 de julho de 1950.

\section{A negritude polêmica}

A visão domesticada da negritude, encabeçada no TEN por Guerreiro Ramos, em meados de 1950, não era, entretanto, a única existente à época. Tal fato fica evidente na polêmica criada em torno da tese da negritude defendida por Ironides Rodrigues no I Congresso do Negro Brasileiro, em 1950.

Deflagrado em um momento de efervescência política do teatro negro, este congresso foi um grande evento público, realizado entre 26 de agosto e 2 de setembro de 1950. Entre outros, ele contou com a participação: a) dos líderes do TEN e de outras organizações negras como Ironides Rodrigues, Abdias do Nascimento, Guerreiro Ramos, Sebastião R. Alves, Guiomar F. Mattos, Aguinaldo Camargo, Pompílio da Hora, Rubens da S. Gordo, Alvarino Castro; b) de apoiadores e colaboradores próximos ao TEN, como o deputado Hamilton Nogueira; c) de um número considerável de estudiosos e intelectuais - Luiz A. Costa Pinto, Edison Carneiro, Darcy Ribeiro, Roger Bastide, Charles Wagley, Carlos G. Krebs. Além desses, esteve presente uma centena de participantes anônimos, que testemunharam o maior evento público organizado sob auspícios do TEN.

Ironides Rodrigues apresentou suas ideias a respeito da negritude no quinto dia de debates (1/9/1950), com a conferência "Uma estética da negritude”. Infelizmente, segundo Abdias (1982, 2003), as Atas desta sessão foram definitivamente extraviadas. A única fonte disponível sobre o que o autor defendeu ali , salvo melhor juízo, são as seguintes passagens do livro $O$ negro no Rio de Janeiro ([1953] 1998) de Costa Pinto: "Na tese de Ironides Rodrigues, apresentada ao Congresso do Negro, o problema da negritude é abordado do ponto de vista particular da estética. E essa aplicação consiste em afirmar que o negro, em consequência de atributos específicos de raça, tem uma sensibilidade hiperdesenvolvida, que o predestina à música, à poesia, à literatura, ao canto, em suma, às artes (p. 257)". E, mais adiante, no mesmo livro: "Ironides, no correr dos debates, reconheceu ter sofrido alguma influência do existencialismo de Sartre, através de um artigo, Orfeu Negro, que ele traduziu para Quilombo" (p. 269). 
Com base nessas informaçóes e na análise dos artigos de Ironides para o Quilombo, o sociólogo Marcio Macedo (2005, p. 211) acredita que o autor entendia a negritude como "racismo antirracista", na linha do pensamento de Sartre. Nesse sentido, a polêmica teve, no Congresso, um papel deflagrador das divergências em torno da noção de raça, projeto de nação mestiça e cientificidade, trazendo à tona uma polarização entre grupos de esquerda nacionalista - como Costa Pinto, Edison Carneiro, Darcy Ribeiro e outros - e grupos de centro-direita populista reformista - reunindo ex-integralistas como Abdias do Nascimento, Guerreiro Ramos e outros (Idem, p. 244).

De fato, pelas fontes disponíveis - reunidas principalmente no livro de Abdias $O$ negro revoltado (1968) -, parece que esta sessão registrou um debate decisivo, sendo, inclusive, o pivô da discussão posterior entre os membros do TEN e a intelectualidade acadêmica sobre a chamada Declaração dos Cientistas, apresentada no último dia do evento. Tanto Abdias como Guerreiro, participantes da sessão, atestam tal hipótese. No artigo "Herói da negritude", Guerreiro torna públicas as divergências em torno do termo negritude:

Os que participaram do Primeiro Congresso do Negro Brasileiro hão de lembrar-se da figura de Aguinaldo Camargo na noite em que se discutia a tese da de Ironides Rodrigues sobre "A Estética da Negritude". A palavra caiu no meio da assembleia como um espantalho. Viram nela um propósito racista de exaltação do negro. Aguinaldo foi dos poucos que percebeu o valor catártico ou psicanalítico do termo. Foi nesse dia, que ele defendeu sua tese segundo a qual é preciso "reeducar o branco", no sentido de adestrá-lo para a convivência democrática com os homens de cor, de minar e desfazer os seus estereótipos e sua ideologia racial discriminativa, que se manifesta até em seu inconsciente, por exemplo, quando associa à cor preta significados pejorativos, elaborados em contextos históricos já ultrapassados. Reeducar o branco para perceber a beleza negra e estimá-la, como uma realidade intrínseca (Guerreiro Ramos, 1952, p. 3).
Abdias é mais específico em sua descrição. $\mathrm{Na}$ apresentação das Atas do Congresso de 1950, o ex-líder do TEN se refere àquela sessão do seguinte modo:

Édison Carneiro jamais poderia emitir conceitos transcritos, emitidos à raiz da discussão, que, no I Congresso Nacional do Negro Brasileiro, se fez da tese de Ironides Rodrigues "A Estética da Negritude". Tanto Édison Carneiro como L. A. Costa Pinto se insurgiram, negaram a Negritude, e tentaram mesmo levá-la ao ridículo. Com a publicação do volume em preparo, Negritude polêmica, a sair brevemente, se constatará, através das notas taquigrafadas, a consagração pelo Congresso em peso - o povo negro, o povo-massa-de-cor - do conceito de Negritude, numa lúcida antecipação do fenômeno histórico que conduziu as naçóes africanas à afirmação de sua independência (Nascimento, [1968] 1982, p. 99).

Mesmo dado por alguém envolvido diretamente com os acontecimentos do Congresso, e, portanto, sob o risco de distorcer de alguma forma os fatos, o depoimento de Abdias é revelador, uma vez que endossa o papel ativo de Edison Carneiro e de Luiz A. Costa Pinto nos debates em torno da negritude. Isso é corroborado quando Aguinaldo Camargo insinua, na última sessão do Congresso, um dia após a discussão da tese de Ironides Rodrigues, que a chamada Declaração dos Cientistas seria fruto do interesse político-partidário do Partido Comunista Brasileiro $(\mathrm{PCB})^{4} \mathrm{em}$ comandar aquele Congresso, atribuindo tal conduta aos supostos autores declaração - Edison Carneiro e Luiz A. Costa Pinto.

Quero afirmar muito seriamente e quero que conste dos Anais o seguinte: é que no movimento negro sempre apareceram elementos de última hora com moçôes do tipo da que acabamos de ver. Em 1945, Raimundo Souza Dantas, antes de se converter ao cristianismo, entrou no movimento com uma ordem de levar todos os negros para um determinado lugar. Esse escritor, naquela época, era analfabeto. Em São Paulo apareceu declaração idêntica feita pelo Sr. Luís Lobato. E agora aqui aparece tra- 
zida pelos Srs. Édison, Costa Pinto, etc. Penso que elementos como o Sr. Lobato, Abatiguara, etc. têm um laço comum para destruir o que se pretende fazer. Parecem tem um laço comum político. Nós queremos dizer que somos antirracistas e contrários a essa corrente político-partidária. Nós precisamos é unir a família negra, unir a família brasileira, para maior felicidade do homem, conforme fiz a ver em meu discurso (Nascimento, [1968] 1982, p. 397).

O fato de Aguinaldo Camargo assinalar, em 1950, que Edison Carneiro e Luiz A. Costa Pinto eram os autores da Declaração dos Cientistas, reforça o argumento posterior de Abdias (1982), de que eles teriam se oposto aos ideais da negritude no dia anterior, quando se discutia a conferência de Ironides Rodrigues.

Tendo-se em conta esses depoimentos, a origem da Declaração dos Cientistas não teria sido algo preestabelecido - como levantado por Aguinaldo Camargo -, mas fruto das divergências ocorridas no penúltimo dia do Congresso. De acordo com Abdias, é crível que esse debate tenha se polarizado em dois grupos divergentes: o grupo de intelectuais, em especial, Edison Carneiro e Luiz A. Costa Pinto, e o grupo da intelligentsia negra do TEN, em particular, Ironides, Abdias e Aguinaldo Camargo. É a partir daí que podemos entender o que levou o grupo intelectual/acadêmico a redigir a Declaração dos Cientistas, em que os signatários se esforçam em se eximir de qualquer responsabilidade sobre os possíveis desdobramentos políticos do I Congresso do Negro Brasileiro. Havia o perigo, aos olhos daquela intelectualidade, de se incorrer no "racismo às avessas", atribuído ao mito da negritude. Esse é o sentido que se pode observar dos seguintes pontos da referida Declaração:

Os congressistas abaixo-assinados consideram do seu dever, em vista das suas responsabilidades como homens de ciência, fazer a seguinte declaração:

I - Não acreditam os signatários desta Declaração na superioridade de raças. Por esta razão, não se consideram ligados, nem comprometi- dos, de maneira alguma, com qualquer teoria que advogue, ainda que no ínfimo particular, qualquer tipo de gradação física, intelectual ou emotiva, entre esses mesmos grupos humanos.

II - Consideram os signatários que os caracteres físicos, intelectuais e morais dos homens são produto da interação de fatores vários, do que certamente o grupo racial participa, mas que não dependem, nem principal nem exclusivamente, dele. [...] O negro brasileiro, por exemplo, embora ainda conserve reminiscências africanas em certas atitudes sociais, já constitui um ser fundamentalmente brasileiro, parte da cultura nacional do Brasil, que provavelmente encontraria sérias dificuldades para se adaptar novamente à vida na África. Assim, os abaixo assinados não se sentem solidários, nem comprometidos, com qualquer teoria que faça tábua rasa do ambiente físico, das condiçôes econômicas e sociais, das instituiçōes políticas, das situações históricas e de outras contingências da vida em sociedade, para ressaltar apenas o aspecto racial, cientificamente falho, inseguro e perigoso, na apreciação dos fenômenos de nosso tempo.

III - Esperam, sinceramente, os signatários que os congressos dessa natureza sirvam à ciência, à determinação de uma atitude correta diante dos fatos sociais e humanos, à fraternidade de todos os povos. [...] Os signatários consideram que trairiam os seus ideais e renegariam todo o cabedal de conhecimentos e objetivos acumulados pela humanidade se, por ocasião ou por omissão, tivessem a desgraça de contribuir para o acirramento de ódios e rivalidades injustificáveis entre os homens, com o ressurgimento do racismo, sob qualquer das suas formas (Nascimento, [1968] 1982, pp. 399-400).

É evidente que, marcado por uma linguagem antirracista dúbia, mais preocupada com o possível "racismo às avessas" do que com o racismo real, a Declaração dos Cientistas era uma afronta à posição teórica e política a respeito da negritude defendida pelos organizadores do Congresso. A crítica era direcionada particularmente aos mem- 
bros ilustres do TEN, Ironides Rodrigues, Aguinaldo Camargo e Abdias do Nascimento. Naquele contexto, portanto, assinar tal documento era, de fato, se colocar contra os ideais da negritude daqueles militantes.

A Declaração foi apresentada pelo historiador Carlos Galvão Krebs, que, ao terminar a leitura, recebeu o apoio público de Hamilton Nogueira (então presidente da mesa), Aguinaldo Camargo e Darcy Ribeiro, que também assinaram o documento. Tudo leva a crer que a Declaração foi tida, a princípio, positivamente pelos membros da assembleia.

$\mathrm{O}$ primeiro que se deu conta do que estava acontecendo foi Abdias do Nascimento:

Estranhei muitíssimo o aparecimento dessa outra declaração, porque parece-me que tudo o que está nela inscrito ficou bem estabelecido nos princípios do nosso Congresso. Tal declaração vem dar ideia de divisão dentro do Congresso. Na nossa declaração de princípios já se frisou muito bem que não somos racistas. Quero deixar bem claro que esta declaração me causa profunda estranheza e que fique consignado em ata o meu pensamento (Nascimento, [1968] 1982, p. 394).

Ao final de sua fala, Abdias põe-se a ler um poema da negritude francófona (não identificado em Atas). 5 Era um ato que, sem dúvida, reforçava seu compromisso teórico e político com uma visão mais afirmativa do negro. O comentário de Abdias voltou à tona na voz de Sebastião Rodrigues Alves, seu antigo colega de militância negra. Após reler a Declaração dos Cientistas, Alves decidiu pedir explicações sobre as intençōes do documento, o que levou Aguinaldo Camargo rever sua posição e retirar sua assinatura da Declaração. A polêmica instaurou-se no Congresso.

Diante da situação, o deputado Hamilton Nogueira, a exemplo de Aguinaldo Camargo, não só retirou sua assinatura, como resolveu, tendo em vista suas prerrogativas como presidente da mesa, arquivar o polêmico documento, e mais, fez com que a Declaração de Princípios, redigida pelas lideranças do TEN, se tornasse o documento de fechamento do Congresso.
Todo este embate enterrou definitivamente $o$ desejo de Abdias e outros líderes negros em transformar o I Congresso do Negro Brasileiro em uma aliança concreta entre as elites políticas e culturais e a intelligentsia do TEN. Afinal, a proposta de uma visão afirmativa da negritude era uma posição que os acadêmicos ali presentes não estavam dispostos a aceitar, a não ser Guerreiro Ramos, que já era membro do TEN

Guerreiro merece aí uma atenção especial. Durante o último dia do Congresso, ele praticamente não se pronunciou, conforme as fontes disponíveis. Mas, ao final do evento, para surpresa dos líderes do TEN, ele assinou a Declaração dos Cientistas, mesmo após seus colegas a terem rejeitado. Constavam, ainda, no documento, as assinaturas de Edison Carneiro, Luiz A. Costa Pinto, Carlos Krebs, Darcy Ribeiro, Walfrido Moraes, Joaquim Ribeiro, Pedro Schoonakker e Amaury Porto de Oliveira.

Como lembra Abdias, o embate em torno da negritude trouxe consequências diretas para a formação de uma postura mais altiva do movimento negro nos anos de 1950. Para os intelectuais do TEN, esta postura esteve associada, entre outras coisas, a uma inspiração política advinda do ideal da negritude que, a partir de então, torna-se mais afirmativa e autônoma. Nas palavras do líder do TEN:

A négritude proporcionara ao movimento de libertação dos países africanos grande impulso histórico e fonte de inspiração. Ao mesmo tempo, influenciou profundamente a busca de caminhos de libertação dos povos de origem africana em todas as Américas, prisioneiros de um racismo cruel de múltiplas dimensôes. No Brasil, enfrentando o tabu da "democracia racial", o Teatro Experimental do Negro era a única voz a encampar consistentemente a linguagem e a postura política da négritude, no sentido de priorizar a valorização da personalidade e cultura específicas ao negro como caminho de combate ao racismo. Por isso, o TEN ganhou dos porta-vozes da cultura convencional brasileira o rótulo de promotor de um suposto racismo às avessas, fenômeno que invariável e erroneamente associavam ao discurso da négritude (Nascimento, 2004, p. 218, grifos originais). 
Essa visão de Abdias, espécie de manifesto à causa dos militantes do teatro negro, será analisado a partir do pensamento de Guerreiro Ramos, após $1950{ }^{6}$

\section{A negritude afirmativa}

Terminado o I Congresso do Negro Brasileiro, Guerreiro passou por um momento difícil em suas relações com a liderança do TEN. Houve certamente uma "quebra na confiança mútua" que marcara sua amizade com Abdias, Ironides, Aguinaldo Camargo e outros integrantes do TEN (Nascimento, 2003). Tratava-se também de uma crise política. Como poderia o diretor do Instituto Nacional do Negro se colocar publicamente a favor da Declaração dos Cientistas (consequentemente, contra a Declaração Final do Congresso, redigida pelas lideranças negras), em um Congresso organizado pelo TEN?

As relações políticas e pessoais de Guerreiro com a liderança do TEN deterioraram-se sensivelmente após o Congresso de 1950. Entretanto, em dezembro do mesmo ano, Guerreiro publicou no periódico $A$ Manhã dois artigos nos quais começa a rever sua posição: "Os estudos sobre o negro brasileiro" e "Senhores e escravos no Brasil". Ele passa a criticar certa tradição do pensamento social brasileiro, que produziria uma imagem idílica do negro e do nosso passado escravista. Tese que considera as relações senhor-escravo e branco-negro mais pacíficas aqui no Brasil em comparação com outras sociedades. Tratava-se de uma mistificação que, nas palavras irônicas de Guerreiro, talvez encontrasse explicação à luz da "sociologia do reconhecimento". Para o autor, tal perspectiva "acadêmica" e "inócua" sobre o assunto deveria ser superada por uma visão mais "dinâmica" do negro. No primeiro artigo, transcreve a Declaração Final do Congresso de 1950 como ponto de partida para a construção de uma sociologia do negro menos estanque e fantasiosa. Foi como um ato público em favor das teses do TEN, dois meses após o Congresso.

A nova posição de Guerreiro, cada vez mais afirmativa e original sobre o tema da negritude, vai se fortalecendo ao longo da década de 1950, o que fica claro em escritos, como "O problema do negro na sociologia brasileira" (1954), "O ne- gro desde dentro" (1954) e "A patologia social do branco brasileiro" (1955). ${ }^{7}$ O ponto de virada encontra-se no ensaio "Um herói da negritude", publicado no Diário de Notícias em abril de 1952, por ocasião da morte de Aguinaldo Camargo, seu amigo. Diz Guerreiro:

Quem se propuser fazer a história das ideias no Brasil terá de registrar como uma das mais revolucionárias e ricas de implicações, aquela que define melhor o movimento do Teatro Experimental do Negro - a ideia da negritude.

É todo um humanismo que se contém nessa ideia-força, um humanismo que postula um niger sum, na mesma acepção em que Tertuliano afirmava o seu homo sum, isto é, uma comoção idiossincrática do universo, resultante de uma peculiaríssima compenetração de fatores biológicos, semelhante, por exemplo, às circunstâncias, à cosmovisão judaica.

Oferece este humanismo a todo negro, a todo mestiço uma verdadeira terapêutica espiritual, a libertação do medo e da vergonha de proclamar sua condição racial, a possibilidade de desmoralizar os equívocos em torno do homem de cor, suscitado por uma longa etapa da história do Ocidente. Este patrimônio espiritual não se perderá, pois que, a sua criação e seu enriquecimento tem custado ate o martírio. Não foi outra coisa Aguinaldo Camargo senão um mártir da negritude. $[\ldots]$

A negritude encontra-se em sua fase heroica. Os homens que vivem seu pathos são uns solitários, são criaturas paradigmáticas como Aguinaldo Camargo; esse Aguinaldo que antes de morrer pediu que vestissem o seu cadáver com seu smoking. Ele não era um plebeu. Era um príncipe da negritude (Guerreiro Ramos, 1952, p. 1).

No cerne dessa nova percepção estava o conceito de niger sum, que segundo Guerreiro, significava um processo de libertação psicológica a ser alcançado por todo aquele negro ou "mestiço" interessado 
em livrar-se do medo e da vergonha de proclamar sua condição étnica, tão pejorativamente tratada na história do Ocidente. Todavia, para o autor, esse processo estaria ainda restrito a uma elite intelectual, capacitada a atingir sua profundidade espiritual. Em suas palavras: "Durante muito tempo, a negritude será uma elaboração cultural cuja fruição se restringirá a um pequeno grupo de intelectuais. Nem as massas pigmentadas nem as elites brancoides do país estão em condições de assimilar todas as implicaçôes deste valor" (Idem, ibidem). Tal restrição estaria ligada a hábitos e modos de pensar enraizados na sociedade brasileira. "É compreensível que a tese da negritude tenha suscitado irritação e incompreensão. Ela se choca de encontro a hábitos e pensar muito inveterados em nosso meio, os quais têm recebido a sanção das personalidades mais relevantes" (Idem, ibidem).

Entre 1953 e 1955, Guerreiro vai consolidando uma visão dialética da negritude, a partir do conceito de niger sum, que, aparentemente, se aproxima da visão sartriana da negritude - negritude como antítese do supremacismo branco (tese); passo primordial para a criação de uma sociedade a-racial (síntese) (Sartre, 1960, p. 145). Entretanto, a negritude de Guerreiro se diferencia daquela em um ponto fundamental. Para ele, a "tese" não seria o supremacismo branco, mas a afirmação da negritude (o niger sum). Daí Guerreiro afirmar que o niger sum seria uma hermenêutica do negro ([1957] 1995, p. 199). É o lugar da enunciação afirmativa, em que todo homem de pele escura inicia sua libertação humanista.

Essa visão dialética, conforme exposto no ensaio "O negro desde dentro" (1954), comportaria ao menos três elementos complementares: a) niger sum, a assunção da negritude pelo homem de pele escura (tese); b) suspensão da brancura como ideologia dominante (antítese); c) compreensão humanística do valor objetivo da negrura e da luta negra (síntese). Em suma, estava traçado o caminho pelo qual o homem e a mulher de "pele escura" poderia tornar-se uma "pessoa”. Ou seja, um indivíduo que se percebe e age para além da unidimencionalização social (e racial). É esta visão dialética da negritude que chamamos, em outra ocasião, de "personalismo negro" (Barbosa, 2004, 2006).
Por um lado, esse enfoque humanista - não essencialista - sobre o negro é uma das razões que levou Guerreiro Ramos a destacar, nos ensaios reunidos em Introdução crítica à sociologia brasileira (1957) a problemática psicológica e estética da identidade étnica. Tanto uma como outra, para o autor, seriam objetos de estudo fundamentais para um pesquisador que buscasse entender a afirmação individual do "negro" e do "branco". Afinal essa classificação é oriunda de um processo histórico de diferenciação e dominação étnica dos eurodescendentes no país. Esta é a origem das críticas pioneiras de Guerreiro à ideologia da brancura e ao eurocentrismo.

Por outro lado, Guerreiro, entre 1953 e 1954, reforça sua percepção de que a assunção da negritude deveria ser entendida como parte da luta mais ampla dos povos do Terceiro Mundo, pela conquista de suas "personalidades coletivas", independentes da dominação imperialista europeia. Daí que, para o autor, a negritude possuiria um caráter internacionalista. No Brasil, essa conquista significaria a renovação de uma brasilidade nacional-popular, com um povo mestiço afirmando seus valores estéticos e existenciais próprios (Guerreiro Ramos, [1958] 1996, p. 49). ${ }^{8}$ Em suma, a apropriação da negritude seria um passo primordial para à brasilidade.

Isso mostra que, mesmo quando Guerreiro tratava diretamente da temática da negritude, ele estava, de fato, pensando-a sob o signo da Nação. A negritude seria um caminho não só para a integração nacional, mas também para sua inserção na luta terceiro-mundista internacional. Isto explica porque ele cita poucos autores da negritude francófona em seus textos da década de 1950. Afinal, a diferença da "raça", que se poderia interpretar dos textos da negritude francófona, deveria ser transformada em força integradora da Nação. É, nesse sentido, que Guerreiro cita A. Césaire, em seu livro Redução sociológica:

Esses quadros, de que são representantes Diop (Cheikh Anta Diop), Césaire (Aimé Césaire) e Ly (Abdoulaye Ly), vivem um momento que poderia ser considerado "fichtiano". Sentem-se convocados a um empreendimento de fundação histórica, e procurando contribuir, pelo 
esclarecimento, para que as comunidades a que pertencem venham constituir personalidades culturais diferenciadas no nível da univesalidade. Por isso, falam em "nação", que é a mais eminente forma contemporânea de existência histórica, e em "condição humana" para as massas afro-asiáticas, ainda estigmatizadas por extrema pauperização (Guerreiro Ramos, [1958] 1996, p. 50).

Esta forma de apropriação da negritude, insuflando a luta nacionalista, lembra a abordagem do célebre Frantz Fanon em Los condenados de la tierra (2001). Ali também, o revolucionário martiniquense defendia que a negritude deveria ser vista como um elemento da cultura e da consciência nacional. Esta sim, tida como o verdadeiro catalisador das transformações históricas nos países colonizados ou neocolonizados (Idem, pp. 194ss). Nesse sentido, os autores partilhavam de uma visão renovada da negritude, a saber, servir aos objetivos da luta nacional. ${ }^{9}$ A eventual influência das ideias de Fanon sobre Guerreiro resultaria um estudo analítico interessante, fora, porém, do propósito deste artigo. ${ }^{10}$

Não resta dúvida, entretanto, de que o diálogo de Fanon com a negritude francófona era mais intenso. Sua crítica e renovação das ideias ali contidas foi um processo árduo e problemático, iniciado em Pele negra, máscaras brancas (1951) e finalizado em Condenados da terra (1961). Tratava-se de uma disputa geracional, teórica e política, com graves consequências. No Brasil, para Guerreiro, a negritude francófona parece ter sido mais uma fonte de inspiração do que de inquietaçōes teóricas e políticas. A figura de Sartre, para o sociólogo brasileiro, foi mais importante do que a dos verdadeiros autores da negritude francófona.

\section{Considerações finais}

Este artigo tratou inicialmente da recepção do ideário da negritude francófona no Brasil, analisando sua inserção no TEN entre fins da década de 1940 e início de 1950 com base na relevância de alguns autores e ativistas contemporâneos, em especial, Albert Camus, Efraín T. Bó, Aguinaldo
Camargo, Guerreiro Ramos, Gerardo M. Mourão, Sebastião Rodrigues Alves, Abdias do Nascimento e Ironides Rodrigues.

Em seguida propusemos três fases distintas que marcaram essa recepção, pressupondo as inovações oriundas deste ideário. De início, em 1949, a visão patriótica e domesticada da negritude de Guerreiro Ramos, condicionada por sua tentativa de ratificar o pacto da democracia racial. Posteriormente, a perspectiva da negritude afirmativa de Ironides Rodrigues, tão polêmica no I Congresso do Negro Brasileiro (1950). Por fim, o momento de reformulação dessa visão mais afirmativa e dinâmica por parte de Guerreiro Ramos durante a década de 1950.

Procuramos mostrar que a incorporação da negritude francófona no TEN foi um processo ativo, desde cedo condicionado pelas lutas políticas do movimento negro carioca. Longe de representar mera transplantação de ideias, a incorporação desse ideário se deu de modo crítico, motivando, sobretudo, uma reflexão do negro brasileiro sobre si mesmo e sua posição no mundo. Em suma, o novo ideário serviu mais como fonte de inspiração do que como um programa teórico ou político.

\section{Notas}

1 O TEN foi criado por Abdias do Nascimento em 1944. Nas palavras do seu fundador, o teatro negro tinha por objetivo criar um fórum de luta contra o racismo, nas suas mais variadas esferas (Nascimento, 2004, p. 221). Daí a diversidade e a quantidade de ações que o TEN patrocinou e se viu envolvido entre as décadas de 1940 e 1960, tornando-se, por isso, uma das principais instituiçôes do movimento negro brasileiro da época. Sobre a trajetória do TEN, ver entre outros: Muller (1988); Nascimento (1966, 2003, 2004); Macedo (2005); Birman (1991); Elisa Nascimento (2003).

2 Munanga (1988) analisa esta temática cultural e política como fruto de uma confluência contraditória de aspectos internos da luta negra na diáspora desde a obra e a práxis de pensadores negros, como: a) W. E. B. Du Bois e o Pan-africanismo; b) Langston Hughes, Richard Wrigth e o Harlem Renasseince; assim como obras de escritores antilhanos como Price-Mars, Ainsi parla l'oncle (1928), e René Maran, Batouala (1921); 
c) a frustação dos intelectuais negros diante do humanismo ocidental. Além desses fatores internos à diáspora negra, Munanga destaca alguns fatores externos: a) o sentimento trágico das duas Guerras Mundiais; b) a apropriação da arte africana pelo movimento cubista; c) a "descoberta" das civilizaçôes africanas pela ciência social europeia, preconizada, especialmente, pelo etnólogo alemão Léo Frobenius.

3 A acolhida do TEN na imprensa carioca não foi majoritariamente positiva. Pelo contrário, ensejou fortes oposições racistas de diversos jornalistas e políticos da época. Sobre o assunto, ver Elisa Nascimento (2003).

4 Aguinaldo não cita diretamente $\mathrm{o}$ PCB nesta fala. Refere-se, entretanto, a um incidente envolvendo Raimundo S. Dantas, em 1945, quando este teria dito que pretendia levar os negros a "determinado lugar". Segundo Abdias (Dyonisios, 1988, p. 117), este lugar era o PCB.

5 Muito provavelmente, trata-se de um dos poemas contidos na antologia organizada por Senghor: $A n$ thologie de la nouvelle poésie négre et malgáche (1948). Afinal, nesta data, não há indicação certa de outras obras da negritude francófona que os integrantes do TEN tivessem acesso.

6 Sobre a obra de Abdias, existe uma bibliografia tratando especialmente da peça Sortilégio, de 1951. Ver os trabalhos de Marcio Macedo (2005), Elisa L. Nascimento (2003), Patricia Birman (1991) e Moutinho (2004). Macedo é quem mais enfatiza esta relação entre a negritude francesa e o pensamento de Abdias, após 1950. Todavia, sobre Ironides, salvo melhor juízo, ainda não existem análises pormenorizadas.

7 Ensaios reunidos no livro Introdução crítica à sociologia brasileira (1957).

8 Apenas na década de 1970, em algumas notas curtas, é que Guerreiro dará um caráter mais diferencialista a esta visão da negritude, entendendo-a, então, como uma assunção da "cultura negra". A esse respeito, ver Barbosa (2004, 2006).

9 Como mostra Renato Ortiz (2003, p. 64), a diferença se encontra no plano político desta luta. Para Fanon, tratar-se-ia de uma revolução nacional-popular, que tem a nação como um mito, uma utopia. Em suas palavras, "um ponto futuro a ser alcançado, que realizaria as potencialidades humanas". Para Guerreiro, a luta nacional se dá no âmbito de uma nação já forma$\mathrm{da}$, em busca do autodesenvolvimento.

10 Como observou Antonio Sérgio A. Guimarães (2008, p. 103), é provável que Guerreiro tenha lido Fanon nesta época, pois era leitor de revistas francesas Présence Africaine, Esprit e Les Temps Moderne - que haviam publicado escritos do autor martiniquense entre 1952 e 1961. No entanto, entre os artigos citados por Antonio Sérgio, apenas dois deles (Fanon, "L'expérience vécu du noir", Esprit, 179: 657-679, maio 1951, e "Le syndrome nordafricain", Esprit, 187: 237-284, fev. 1952) haviam sido publicados até 1954, data em que Guerreiro publicou o artigo "O problema do negro na sociologia brasileira”, na revista Cadernos do Nosso Tempo. Este é um ensaio central sobre relaçôes raciais no Brasil, republicado no livro Introdução crítica à sociologia brasileira (1957). Caberia, pois, uma análise pormenorizada deste assunto, para que se possa definir qual a exata influência (se é que ela existiu) das ideias de Fanon em Guerreiro.

\section{BIBLIOGRAFIA}

BARBOSA, Muryatan S. (2004), Guerreiro Ramos e o personalismo negro. São Paulo, dissertação de mestrado, Departamento de Sociologia, FFLCH/USP.

. (2006), "Guerreiro Ramos e o personalismo negro”. Tempo Social, 18 (6): 217-228.

BASTIDE, Roger. (1961), "Variations on negritude". Présence Africaine, 36: 82-92, jan.-mar.

BÓ, Efraín T. (2003a), "A poesia afro-americana" [1948], in A. Nascimento (org.), Quilombo: vida, problemas e aspiraçôes do negro brasileiro, São Paulo, Fusp/Editora 34. (2003B). "O ator negro" [1949], in A. Nascimento (org.), Quilombo: vida, problemas e aspiraçôes do negro brasileiro, São Paulo, Fusp/ Editora 34

CÉSAIRE, Aimé. (2005), Nègre je suis, nègre je resterai: entretiens avec Françoise Vergès. Paris, Albin Michel.

COSTA PINTO, Luiz A. ([1953] 1998), O negro no Rio de Janeiro: relações de raça numa sociedade em mudança. 3. ed. Rio de Janeiro, Editora da UFRJ.

FANON, Frantz. (1951), "L'expérience vécu du noir". Esprit, 179: 657-667, mai. - (2001), Los condenados de la tierra [1961]. Mexico, DF, Fondo de Cultura Económica.

- (2008), Pele negra, máscaras brancas [1951]. Salvador, Edufba. 
GUERREIRO RAMOS, Alberto. (1952), "Um herói da negritude". Diário de Notícias, Suplemento Literário, Rio de Janeiro, 6 abr. ([1957] 1995). Introdução crítica à sociologia brasileira. Rio de Janeiro, Editora da UFRJ.

([1958] 1996). Redução sociológica. Rio de Janeiro, Editora da UFRJ.

(2003), "Apresentação da negritude (jun./jul. 1950)”, in A. Nascimento (org.), Quilombo: vida, problemas e aspiraçōes do negro brasileiro, São Paulo, Fusp/Editora 34.

GUERREIRO RAMOS, Alberto; NASCIMENTO, A. et al. (1950), Relaçôes de raça no Brasil. Rio de Janeiro, Quilombo.

GUIMARÃES, Antonio S. (2002). Classes, raças e democracia. São Paulo, Editora 34. (2008). "A recepção de Fanon no Brasil e a identidade negra”. Novos Estudos, 81: 99-114. MACEDO, Marcio. (2005). Abdias do Nascimento: o negro revoltado. São Paulo, dissertação de mestrado, Departamento de Sociologia, FFL$\mathrm{CH} / \mathrm{USP}$.

MOURALIS, Bernard. (1992), "Presénce Africaine: geography of an "ideology", in V. Y. Mudimbe (ed.), The surreptitious speech: Présence Africaine and the politics of otherness: 19471987. Chicago/Londres, University of Chicago Press.

MOUTINHO, Laura. (2004). Razão, "cor" $e$ desejo: uma análise sobre relacionamentos afetivos-sexuais "inter-raciais" no Brasil e na África do Sul. São Paulo, Editora da Unesp.

MULLER, R. G. (1988), "Identidade e Cidadania: Teatro Experimental do Negro”. Dionysios, 28, Brasília, Fundação MinC, número organizado por R. G. Muller.

MUNANGA, Kabengele. (1988), Negritude: usos e sentidos. 2 ed. São Paulo, Ática (série Princípios).

NASCIMENTO, Abdias (org.). ([1968] 1982), O negro revoltado. Rio de Janeiro, Nova Fronteira. (1988). "A energia do inconformismo (depoimento)". Dionysios, 28, Brasília, Fundação MinC, número organizado por R. G. Muller, pp. 90-101.

(org.). (2003), Quilombo: vida, problemas e aspirações do negro brasileiro. São Paulo,
Fusp/Editora 34. . (2004), "Teatro Experimental do Negro: trajetória e reflexões”. Estudos Avançados, 50: 209-224, jan./abr.

NASCIMENTO, Elisa L. (2003), O sortilégio da cor: identidade, raça e gênero no Brasil. Rio de Janeiro, Summus.

ORTIZ, Renato. (2003), Cultura brasileira e identidade nacional. São Paulo, Brasiliense.

RODRIGUES, Ironides. (2003a), "Exotismo literário de Paul Morand", in A. Nascimento (org.), Quilombo: vida, problemas e aspiraçôes do negro brasileiro, São Paulo, Fusp/Editora 34. . (2003B), "Cruz e Souza em outro idioma", in A. Nascimento (org.), Quilombo: vida, problemas e aspiraçôes do negro brasileiro, São Paulo, Fusp/Editora 34.

SARTRE, J. Paul. (1960), Reflexóes sobre o racismo [1948]. São Paulo, Difusão Europeia do Livro.

SENGHOR, Léopold S. (org.). (1948), Anthologie de la nouvelle poésie négre et malgache de langue française. Paris, Presses Universitaires de France. (1992), "Preface", in V. Y. Mudimbe (ed.), The surreptitious speech: Présence Africaine and the politics of otherness: 1947-1987. Chicago/Londres, University of Chicago Press.

WAUTHIER, Claude. (1973), L'Afrique des africains: inventaire de la negritude. 2 ed. Paris, Seuil (col. L'Histoire Immediate).

\section{Depoimentos citados}

COSTA, Haroldo. (2003). Entrevistador: Muryatan S. Barbosa. Reprodução parcial da entrevista in Muryatan S. Barbosa (2004), Guerreiro Ramos e o personalismo negro, São Paulo, dissertação de mestrado, Departamento de Sociologia, FFLCH/USP.

MOURÃO, Gerardo (2003). Entrevistador: Muryatan S. Barbosa. Reprodução parcial da entrevista in Muryatan S. Barbosa (2004), Guerreiro Ramos e o personalismo negro, São Paulo, dissertação de mestrado, Departamento de Sociologia, FFLCH/USP.

NASCIMENTO, Abdias (2003). Entrevistador: Muryatan S. Barbosa. 


\section{O TEN E A NEGRITUDE FRANCÓFONA NO BRASIL: RECEPÇÃO E INOVAÇÕES}

Muryatan Santana Barbosa

Palavras-chave: Teatro Experimental do Negro; Negritude francófona; Guerreiro Ramos; Movimento negro.

A partir da análise das atividades públicas do Teatro Experimental do Negro (TEN) no Rio de Janeiro, entre 1949 e início dos anos de 1950, o artigo investiga a recepção das ideias da negritude francófona no Brasil. Para isso, rastreia as origens, o contexto político do teatro negro e os personagens responsáveis pela tradução dessas ideias. Buscamos mostrar o caráter inovador e heterogêneo de tais apropriações, destacando os ensaios do sociólogo Alberto Guerreiro Ramos na década de 1950.

\section{THE TEN AND THE FRACOPHONE NEGRITUDE IN BRAZIL: RECEPTION AND INNOVATION}

\section{Muryatan Santana Barbosa}

Keywords: Black Experimental Theater; Francophone negritude; Guerreiro Ramos; Black movements.

Starting from an analysis of the TEN (the Black Experimental Theater) activities in Rio de Janeiro, between 1949 and early 1950 , the article investigates the reception in Brazil of the Francophone's ideas of Negritude. With such purpose, it traces the origins and the political context of the Black theater as well as the figures responsible for the reception of such ideas. In so doing, it seeks to show the innovative and heterogeneous character of such appropriations, with special emphasis on the essays of sociologist Guerreiro Ramos in the 1950's.

\section{LE THÉÂTRE EXPÉRIMENTAL DU NOIR (TEN) ET LA NÉGRITUDE FRANCOPHONE AU BRÉSIL: RÉCEPTION ET INNOVATIONS}

\section{Muryatan Santana Barbosa}

Mots-clés: Théâtre Expérimental du Noir; Négritude francophone; Guerreiro Ramos; Mouvement noir.

À partir de l'analyse des activités publiques du Théâtre Expérimental du Noir (TEN) à Rio de Janeiro, entre 1949 et le début des années 1950, l'article aborde la réception des idées de la négritude francophone au Brésil. Il recherche, pour cela, les origines, le contexte politique et du théâtre noir et les personnages responsables pour la traduction de ces idées. Nous tentons de démontrer le caractère innovateur et hétérogène de telles appropriations en nous fondant, principalement, sur les textes du sociologue Alberto Guerreiro Ramos publiés au cours des années 1950 . 